\title{
Synthesis, characterization and catalytic of a solid acid supported on amorphous activity carbon
}

\author{
Runjun Huang ${ }^{1, a}$, Huajun Ma ${ }^{1, b}$, Hui Liang ${ }^{2, c}$, Aiqun Yuan ${ }^{2, d^{\star}}$, Wei Xie ${ }^{3, e}$ \\ ${ }^{1}$ Guilin University of Technology at Nanning, Nanning 530001, Guangxi china \\ ${ }^{2}$ School of Chemistry and Chemical Engineering, Guangxi University for Nationalities, Nanning, \\ 530006, China
}

${ }^{3}$ Guangxi Vocational \& Technical Institute of Industry, Nanning, 530004, Guangxi, China

aemail:408620880@qq.com, bemail: 576967@qq.com, ch:huiliang2014@126.com, d:

Corresponding author: aiqunyuan1999@ sina.com, e. 939689284@qq.com

Keywords: Activated carbon; Catalyst support; Catalytic activity; solid acid catalysis

Abstract: Some new heterogeneous catalysts used to synthesize the tributyl citrate (TBC) and aspirin were prepared and characterized by brunauer-emmett-teller (BET), field emission scanning electron microscope (FE-SEM) and X-ray diffraction (XRD). The effect of temperature, catalyst loading and the concentration of oxidants on the catalytic efficiency of the catalyst were investigated. The results show that three ATP/t-AC catalysts namely ATP/t-AC-1, ATP/t-AC-2, ATP/t-AC-3 can be obtained by loading $60 \%$ aluminum dihydrogen tripolyphosphate (ATP) on oxidation modified activated carbon t-AC oxidized by $\mathrm{Na}_{2} \mathrm{~S}_{2} \mathrm{O}_{8}, \mathrm{H}_{2} \mathrm{O}_{2}, \mathrm{HNO}_{3}$ respectively at $603 \mathrm{~K}$. For ATP/t-AC-1, when the concentration of $\mathrm{Na}_{2} \mathrm{~S}_{2} \mathrm{O}_{8}$ increases to $0.75 \mathrm{~mol} / \mathrm{L}$, the yield of aspirin increase to $86.6 \%$ while that of the TBC increase to $93 \%$. For ATP/t-AC-2, when the concentration of $\mathrm{H}_{2} \mathrm{O}_{2}$ adds to $1 \mathrm{~mol} / \mathrm{L}$, the yield of aspirin increase to $86.7 \%$ while that of the TBC increase to 93\%. For ATP/t-AC-3, the yield of TBC increase to $86.7 \%$ while the TBC increase is $97 \%$ with the concentration of $\mathrm{HNO}_{3}$ increases to $0.5 \mathrm{~mol} / \mathrm{L}$. The ATP supported on the AC increase its specific surface area and improved its catalytic activity.

\section{Introduction}

Liquid acids such as $\mathrm{H}_{2} \mathrm{SO}_{4}, \mathrm{H}_{3} \mathrm{PO}_{4}$ and $\mathrm{HF}$ are the most widely used acid catalysts in chemical industry over the past decades. However, the usage of these homogeneous acids cause lots of serious problems such as hazards in transportation, difficulties in separation, waste acid pollution and equipment corruption ${ }^{[1-5]}$.In recent years, much effort has been made in understanding the properties of the heterogeneous catalysis ${ }^{[6-10]}$. Solid catalysts have advantages of easy separation from reactant suspension and reusability. Thus, development of environmentally benign solid catalysts in the place of $\mathrm{H}_{2} \mathrm{SO}_{4}$ is desirable for this reaction ${ }^{[11]}$. ATP is a kind of solid acid that it is Nontoxic, higher acidity, weaker acid strength and that has the $-\mathrm{P}=\mathrm{O}$ and $-\mathrm{P}-\mathrm{OH}$. The ATP used as paint has been studied extensively. But fewer researches have been done on the catalytic of the ATP, because of the smaller surface areas and condition factors. Wang Jing prepared ATP/S-Diatomite by using the method of Diatomite loading S. The surface area of ATP is enlarged by S-Diatomite supporting and the catalytic activity of the ATP has been improved by the method. The ATP/SDiatomite catalyst is used to catalyze the organic reaction and the conversation of citric acid is $96 \%$. Its catalytic performance is even exceeding the sulfuric acid. But the process of the preparation has the subliming of sulfur and the pollution on the environment. The experiment of preparation of ATP/t-AC is high effect, operability and environmental. The conversation of citric acid on ATP/t$\mathrm{AC}$ is $96.8 \%$ and the yield of aspirin is $86.6 \%$ by the catalysis.

Carbon materials such as AC have been considered as good supports for heterogeneous catalysts ${ }^{\text {[12- }}$

${ }^{13]}$. Among the reported catalysts, many efforts are being made to further increase their catalytic performance ${ }^{[14-18]}$. For example, Makowski et al. reported a method for the preparation of hydrophilic carbon supported Pd catalysts, while Matos and Corma focused on the catalytic performance of $\mathrm{TiO}_{2}-\mathrm{C}$ hybrid materials by presenting only a brief discussion on the influence of 
hydrophilicity and hydrophobicity. It is seen that the study of the relationships between the hydrophilicity and catalytic performance is still lacking ${ }^{[19,20]}$. Catalysts made of noble metal supported by activated carbon are of considerable interest due to their applications in various processes such as purification of terephthalic acid and destruction of volatile organic compound (VOC) ${ }^{[21-26]}$. AC is widely used as a raw material in many industrial processes. Activated carbon received more attention due to its excellent catalytic support characteristics for the oxidation of organic compounds and because of its flexibility for supporting catalysts. It is well know that activated carbon adsorbs chemical compounds from aqueous and gaseous phases, because of its high surface area, flexible pore structure and chemical nature of the surface ${ }^{[27-30]}$. Surface characteristics and surface behavior of the catalyst are influenced by carbon-oxygen functional groups. The porous structure and surface chemistry properties of AC are important connection with its adsorbent behavior ${ }^{[31,32]}$. Therefore, some reports show the ACs and CNTs (pretreated with $\mathrm{HNO}_{3}$ ) supported catalysts show the local hydrophilicity of the catalysts can be tuned by treating the carbonaceous supports with $\mathrm{HNO}_{3}$ at various conditions.(oxygen content) ${ }^{[33,34]}$.

In this study, we present the effect of surface performance of the AC supported ATP catalysts on the composition of TBC and aspirin reaction. The hydrophilicity of the AC was tuned by simply pretreating with $\mathrm{Na}_{2} \mathrm{~S}_{2} \mathrm{O}_{8}, \mathrm{H}_{2} \mathrm{O}_{2}$ and $\mathrm{HNO}_{3}$ at various concentrations.

\section{Experimental}

\section{Drug and Instrument}

$\mathrm{H}_{3} \mathrm{PO}_{4}(\mathrm{AR}), \mathrm{Al}(\mathrm{OH})_{3}(\mathrm{AR}), \mathrm{Na}_{2} \mathrm{~S}_{2} \mathrm{O}_{8}(\mathrm{AR}), \mathrm{H}_{2} \mathrm{O}_{2}(30 \%)$ and $\mathrm{HNO}_{3}(65 \%)$ were obtained from Chengdu Kelong Chem. Co; AC(AR) was obtained from Beijin Dali Chem. Co. The X-ray diffractometry (XRD) measurements of the samples were performed on a XD-3 diffractometer (Puxi,Tongyong, Beijin, wavelength $=1.5406 \mathrm{~nm}$ ) at $36 \mathrm{kV}$ and $25 \mathrm{~mA}$. The powder samples were scanned from 10 to $70^{\circ}$. SEM images of t-AC were obtained by a SUPRA 55 scanning electron micrograph machine (Carl ZEISS). BET images of t-AC were obtained by Nitrogen adsorption isotherms (V-Sorb X800).

\section{Preparation of catalysts}

\section{Preparation of Supports}

In this study, The prepared t-AC (10g) was obtained with $\mathrm{Na}_{2} \mathrm{~S}_{2} \mathrm{O}_{8}\left(\mathrm{H}_{2} \mathrm{O}_{2}, \mathrm{HNO}_{3}\right)$ solution $(250 \mathrm{~mL} ; 0.125 \mathrm{~mol} / \mathrm{L}, 0.25 \mathrm{~mol} / \mathrm{L}, 0.5 \mathrm{~mol} / \mathrm{L}, 0.75 \mathrm{~mol} / \mathrm{L}, 1 \mathrm{~mol} / \mathrm{L}, 1.25 \mathrm{~mol} / \mathrm{L})$. The aqueous slurry was stirred $(500 \mathrm{rpm})$ at $333 \mathrm{~K}$ for $6 \mathrm{~h}$ and washed five times with distilled water, dried $(373 \mathrm{~K} ; 12 \mathrm{~h})$. $\mathrm{Na}_{2} \mathrm{~S}_{2} \mathrm{O}_{8}$ pretreated ACs have been denoted as "t-AC-1" or "t-AC-1-x", where x represent the concentrations of $\mathrm{Na}_{2} \mathrm{~S}_{2} \mathrm{O}_{8} . \mathrm{H}_{2} \mathrm{O}_{2}$ pretreated ACs have been denoted as "t-AC-2" or "t-AC-2-x", where $x$ represent the concentrations of $\mathrm{H}_{2} \mathrm{O}_{2}$. $\mathrm{HNO}_{3}$ pretreated ACs have been denoted as "t-AC-3" or "t-AC-3-x", where $\mathrm{x}$ represent the concentrations of $\mathrm{HNO}_{3}$. The ATP without supports supporting have been denoted as ATP-based catalysts.

\section{Preparation of ATP/ut-AC}

The $\mathrm{n}\left(\mathrm{Al}(\mathrm{OH})_{3}\right)=0.1 \mathrm{~mol}, \mathrm{~m}\left(\mathrm{H}_{2} \mathrm{O}\right)=15 \mathrm{~g}, \mathrm{~m}\left(\mathrm{H}_{3} \mathrm{PO}_{4}\right)=34.6 \mathrm{~g}$, and they were reacted in beaker for $35 \mathrm{~min}$ in $383 \mathrm{~K}$ and cooling, then the precursor of ATP was achieved. Refer to the reports, we can prepare $\mathrm{AlH}_{12} \mathrm{P}_{3} \mathrm{O}_{10} \cdot \mathrm{xH}_{2} \mathrm{O}(\mathrm{I})$ and $\mathrm{AlH}_{12} \mathrm{P}_{3} \mathrm{O}_{10}$ (II) in (533K-663K) from the precursor.

\section{Results and discussion}

\section{Catalytic Activity of ATP/ut-AC}

\section{Effect of Preparation temperature on Catalytic Activity of ATP/ut-AC}

Fig1.show the catalytic performance of the ATP/u t-AC catalysts for the synthesis of tributyl citrate and aspirin at different catalysts preparation temperature $(543 \mathrm{~K}, 573 \mathrm{~K}, 603 \mathrm{~K}, 633 \mathrm{~K}, 663 \mathrm{~K})$ separately when the ATP loading is $100 \mathrm{wt} \%[\mathrm{~m}(\mathrm{ATP}): \mathrm{m}(\mathrm{u} \mathrm{t}-\mathrm{AC})=1: 1]$.It is clearly seen that the yield of tributyl citrate and aspirin are $92.5 \%$ and $83 \%$ at $603 \mathrm{~K}$, respectively, which are significantly higher 
than that over the ATP/u t-AC catalysts(preparation at 543K,573K, 633K,663K). The ATP/u t-AC catalysts is prepared at $603 \mathrm{~K}$ that has highest catalytic activity. Their activity increased with the heat treatment from $543 \mathrm{~K}$ to $603 \mathrm{~K}$. In addition, the activity of ATP/u t-AC $(603 \mathrm{~K})$ was higher than that of the ATP-based conventional catalysts.

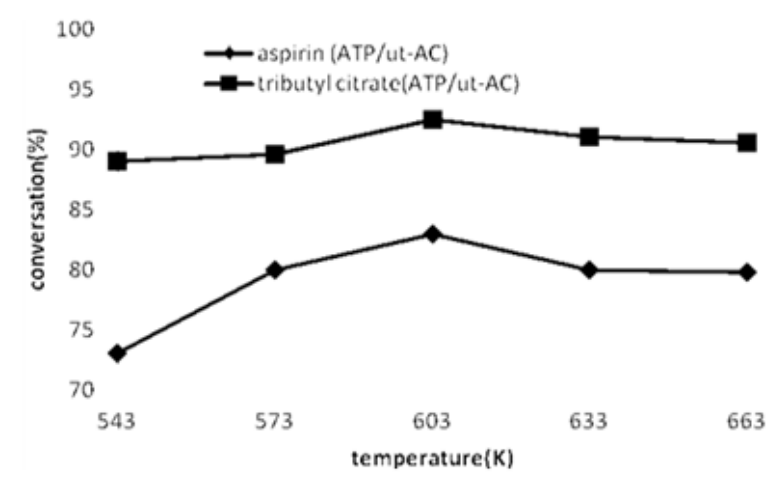

Fig1. Effect of loading temperature on the performance of catalytic activity of ATP/u t-AC for the synthesis of tributyl citrate and aspirin

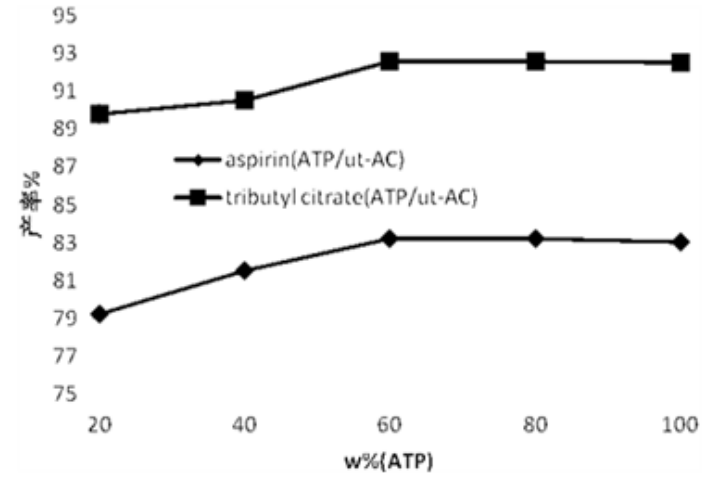

Fig2. Effect of the surface loading of ATP on the performance of catalytic activity of ATP/u t-AC for the generation of tributyl citrate and aspirin

\section{Effect of w\%(ATP)loading on Catalytic Activity of ATP/ut-AC}

Refer to fig2 the catalysts has an significant catalytic activity when the ATP loading is $60 \mathrm{wt} \%$. The surface area of ATP is enlarge by the AC supporting. Refer to previous literatures[19], COchemisorption and XPS results, based on the catalytic activity, it is concluded that the well-loaded ATP mainly contribute to catalytic activity. The catalysts activity was consistent with the loading and surface concentration of loading catalysts. The ATP/u t-AC (20\%) gives the lowest activity due to the lowest surface area and the surface concentration of ATP. The microporous AC supported ATP catalyst must be mentioned that such a difference in the ATP loading $(>60 \%)$ should not highly affect the catalytic performance due to the diffusion limitation since almost all of the ATP particles should be anchored outside of the pores for support.

\section{Effect of $\mathrm{Na}_{2} \mathrm{~S}_{2} \mathrm{O}_{\mathbf{8}}\left(\mathrm{H}_{2} \mathrm{O}_{2}, \mathrm{HNO}_{3}\right)$ concentration on Catalytic Activity of ATP/t-AC}

Refer to Fig. 3 the outcomes of the statistical analysis for the experimental results, the highest yield of TBC is $96.8 \%$ (by $0.75 \mathrm{~mol} / 1 \mathrm{Na}_{2} \mathrm{~S}_{2} \mathrm{O}_{8}$ ). The yield is $91.5 \%$ (by $0.5 \mathrm{~mol} / \mathrm{L} \mathrm{H}_{2} \mathrm{O}_{2}$ ). As the yield is increased within $0.5 \mathrm{~mol} / \mathrm{L}$, and the yield is decreased more than $0.5 \mathrm{~mol} / \mathrm{L}$, the yield is $90.8 \%$ ( by $0.75 \mathrm{~mol} / \mathrm{LHNO}_{3}$ ), The yield is increased within $0.75 \mathrm{~mol} / \mathrm{L}$, and the yield is gradually decreased more than the $0.75 \mathrm{~mol} / \mathrm{L}$.

The yield of aspirin is $86.6 \%$ ( by $1.0 \mathrm{~mol} / 1 \mathrm{H}_{2} \mathrm{O}_{2}$ ). The outcomes of the statistical analysis for the experimental (fig.2), there are more quantities of oxygenated groups, and the pore structure of AC has a bigger change (fig3). The three factors and their interaction have significant effects to the catalytic activity. 

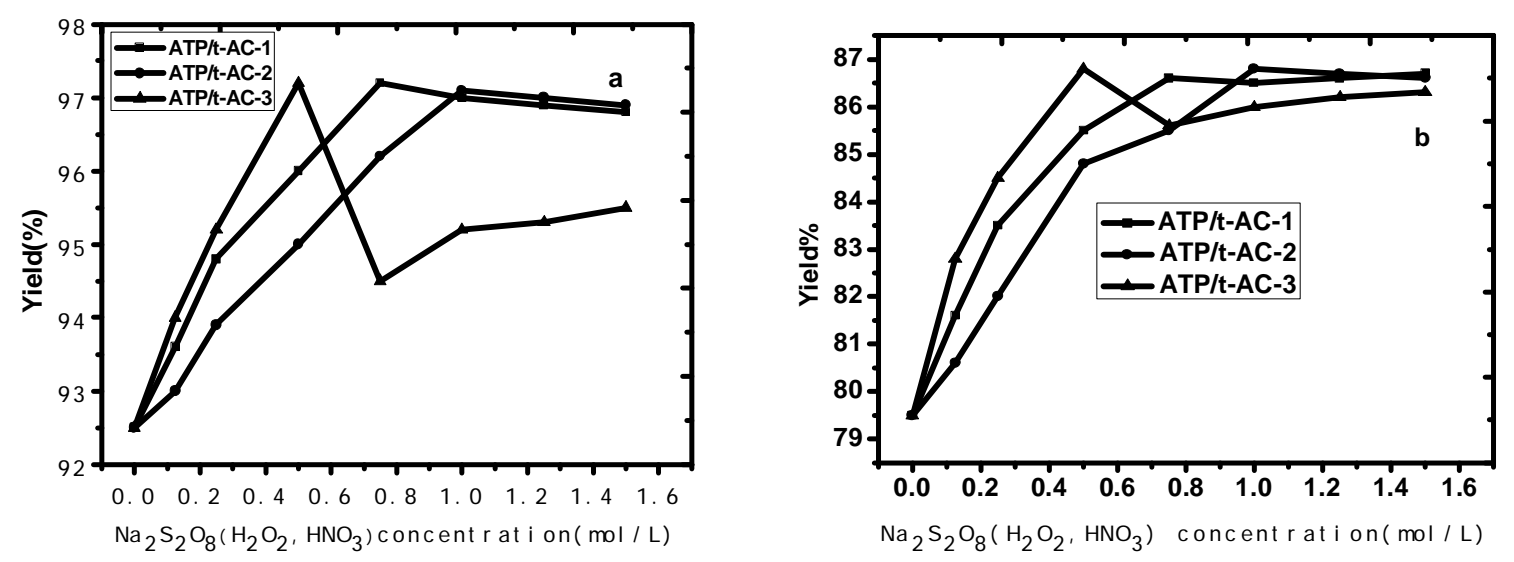

Fig3.Effect of $\mathrm{Na}_{2} \mathrm{~S}_{2} \mathrm{O}_{8}\left(\mathrm{H}_{2} \mathrm{O}_{2}, \mathrm{HNO}_{3}\right)$ concentration on Catalytic Activity of ATP/t-AC for the composition of TBC and aspirin reaction

\section{Characterization of Supports and Catalysts}

\section{BET Studies}

Refer to fig3 (a), When ATP/t-AC-1 was prepared without the addition of $\mathrm{Na}_{2} \mathrm{~S}_{2} \mathrm{O}_{8}$, the yield of TBC was $92.5 \%$. When $\mathrm{Na}_{2} \mathrm{~S}_{2} \mathrm{O}_{8}$ was added, the activity of ATP/t-AC-1 was dramatically increased and the yield of TBC was above94\%.It was found that the activity of ATP/t-AC-1 varied with the concentration $\mathrm{Na}_{2} \mathrm{~S}_{2} \mathrm{O}_{8}$ solution. Its activity was increased steadily when the concentration of $\mathrm{Na}_{2} \mathrm{~S}_{2} \mathrm{O}_{8}$ less than $0.75 \mathrm{~mol} \mathrm{~L}^{-1}$. When the concentration of $\mathrm{Na}_{2} \mathrm{~S}_{2} \mathrm{O}_{8}$ was increased to $0.75 \mathrm{~mol} / \mathrm{L}$, its activity increased with concentration of $\mathrm{Na}_{2} \mathrm{~S}_{2} \mathrm{O}_{8}$ increasing and the yield of TBC was $96.9 \%$. The activity of ATP/t-AC-1 decreased a little above $0.75 \mathrm{~mol} / \mathrm{L}$ of $\mathrm{Na}_{2} \mathrm{~S}_{2} \mathrm{O}_{8}$ solution. Then the catalytic activity was steadily not changed with the concentration of $\mathrm{Na}_{2} \mathrm{~S}_{2} \mathrm{O}_{8}$ solution increasing. The activity of ATP/t-AC-2 was similar to ATP/t-AC- 1 . When $\mathrm{H}_{2} \mathrm{O}_{2}$ was added, the activity of ATP/tAC-2 was dramatically increased and the yield of TBC was above $93 \%$. When the concentration of $\mathrm{H}_{2} \mathrm{O}_{2}$ was increased to $1 \mathrm{~mol} / \mathrm{L}$, its activity increased with concentration of $\mathrm{H}_{2} \mathrm{O}_{2}$ and the yield of TBC was $97 \%$. The activity of ATP/t-AC-2 was not changed above $1 \mathrm{~mol} / \mathrm{Lof} \mathrm{H}_{2} \mathrm{O}_{2}$ solution. The ATP/t-AC-3 was prepared, the yield of TBC was increased to $97 \%$ with the concentration of $\mathrm{HNO}_{3}$ was increased to $0.5 \mathrm{~mol} / \mathrm{L}$. The activity of ATP/t-AC-3 decreased to $94.3 \%$ above $0.5 \mathrm{~mol} / \mathrm{L}$ of $\mathrm{HNO}_{3}$ solution. While the activity of ATP/t-AC-3 increased to $95.3 \%$ with the concentration of $\mathrm{Na}_{2} \mathrm{~S}_{2} \mathrm{O}_{8}$ solution increased to $0.75 \mathrm{~mol} / \mathrm{L}$, then the activity of ATP/t-AC-3 is not changed steadily with the concentration of $\mathrm{HNO}_{3}$ increasing. In order to further study the effect of concentration of oxidants $\left(\mathrm{Na}_{2} \mathrm{~S}_{2} \mathrm{O}_{8}, \mathrm{H}_{2} \mathrm{O}_{2}, \mathrm{HNO}_{3}\right)$ solution, the effect of $\mathrm{Na}_{2} \mathrm{~S}_{2} \mathrm{O}_{8}\left(\mathrm{H}_{2} \mathrm{O}_{2}, \mathrm{HNO}_{3}\right)$ concentration on Catalytic Activity of ATP/t-AC for the composition of aspirin was studied and shown in fig 3(b). When $\mathrm{Na}_{2} \mathrm{~S}_{2} \mathrm{O}_{8}$ was added, the activity of ATP/t-AC-1 was dramatically increased and the yield of aspirin was above $79.5 \%$. Its activity was increased steadily when the concentration of $\mathrm{Na}_{2} \mathrm{~S}_{2} \mathrm{O}_{8}$ less than $0.75 \mathrm{~mol} / \mathrm{L}$. When the concentration of $\mathrm{Na}_{2} \mathrm{~S}_{2} \mathrm{O}_{8}$ was increased to $0.75 \mathrm{~mol} / \mathrm{L}$, the yield of aspirin was increased to $86.6 \%$. The activity of ATP/t-AC-1 was steadily above $0.75 \mathrm{~mol} / \mathrm{Lof}$ $\mathrm{Na}_{2} \mathrm{~S}_{2} \mathrm{O}_{8}$ solution. When $\mathrm{H}_{2} \mathrm{O}_{2}$ was added, the activity of ATP/t-AC-2 was dramatically increased and the yield of aspirin was increased to $86.7 \%$ with the concentration of $\mathrm{H}_{2} \mathrm{O}_{2}$ increasing to $1 \mathrm{~mol} / \mathrm{L}$. The activity of ATP/t-AC-2 was not changed above $1 \mathrm{~mol} / \mathrm{Lof} \mathrm{H}_{2} \mathrm{O}_{2}$ solution. The activity of ATP/t-AC-3 was increased to $86.7 \%$ with the concentration of $\mathrm{HNO}_{3}$ increased to $0.5 \mathrm{~mol} / \mathrm{L}$. The activity of ATP/t-AC-3 decreased a little above $0.5 \mathrm{~mol} / \mathrm{L}$ of $\mathrm{HNO}_{3}$ solution. Then the activity of ATP/t-AC-3 is not changed steadily with the concentration increasing. 

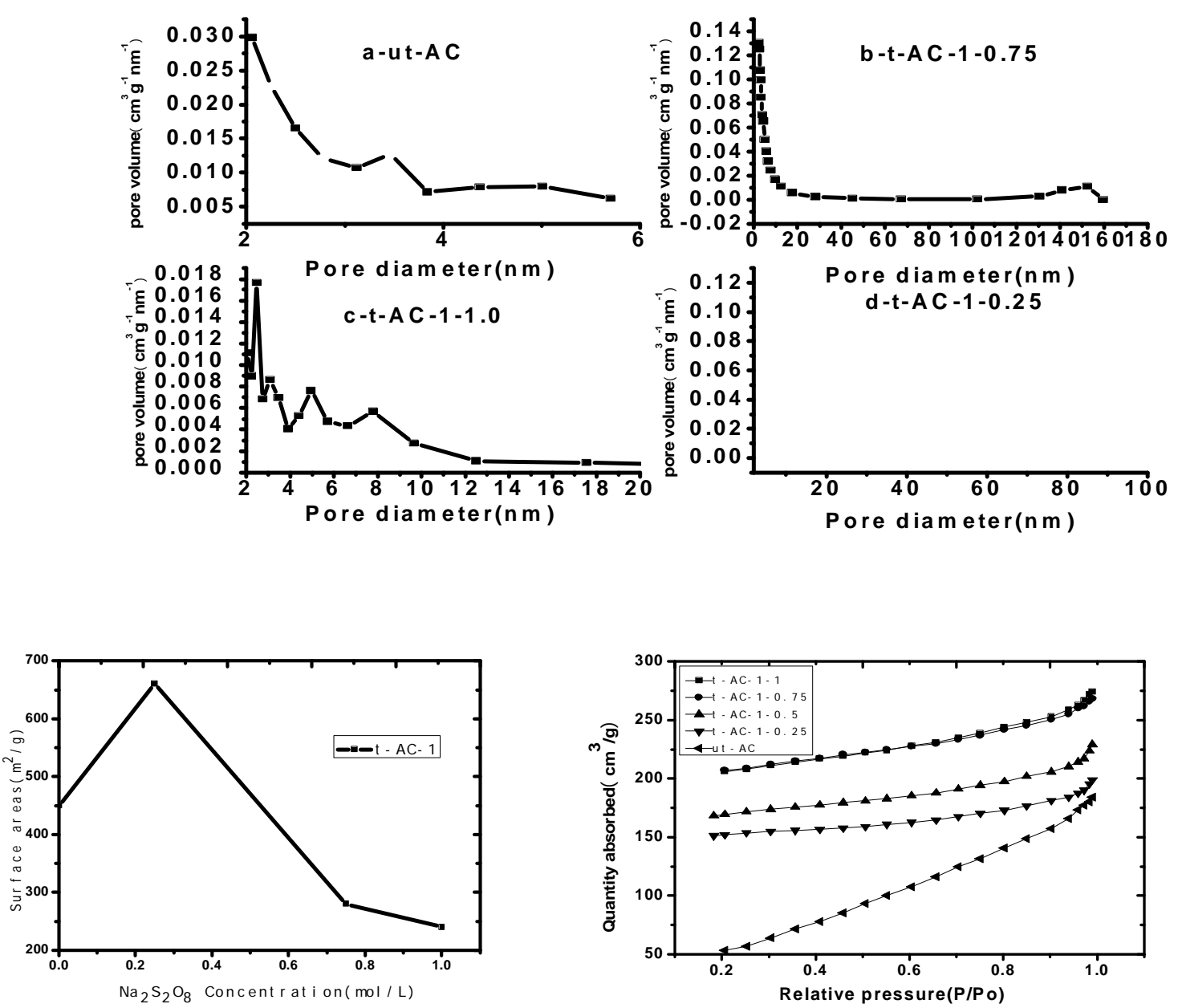

Fig4.pore size distribution and surface areas of $\mathrm{u} t-$ AC,t-AC-1-0.25,t-AC-1-0.75,t-AC-1-1.0

Fig.5 Nitrogen adsorption isotherms of t-AC

Take t-AC-1- as examples, fig4 shows the pore size distribution of $\mathrm{u}$ t-AC was far narrower than that of the t-AC. The surface areas and pore size distribution suggested that the samples were micropores materials. The pore size distribution of the t-AC-1 were wider with the concentration of $\mathrm{Na}_{2} \mathrm{~S}_{2} \mathrm{O}_{8}$ increasing . Refer to the previous literatures ${ }^{[25]}$, it is also expected that the hydrophilicity of the $\mathrm{AC}$ should be increased through pretreating the $\mathrm{u}$ t-AC with oxidants solution at various conditions (by controlling the oxidants solution concentration).. The activity of ATP/t-AC-1-0.75 was also maximum (fig3a, b). Based on our and other theoretical studies, the AC supported the ATP mainly has chemical adsorption and physisorption. The chemical adsorption on the AC by the chemical bonding between the oxygen-containing functional group of the $\mathrm{t}-\mathrm{AC}$ and the surface oxygen groups of ATP (-P=, P-OH).

Fig. 5 shows the nitrogen physisorption data of the $\mathrm{t}-\mathrm{AC}$ supports (with different concentration of $\mathrm{Na}_{2} \mathrm{~S}_{2} \mathrm{O}_{8}$ ). The quantity adsorption of the $\mathrm{t}-\mathrm{AC}$ was increased to maximum when the concentration of $\mathrm{Na}_{2} \mathrm{~S}_{2} \mathrm{O}_{8}$ increased to $0.75 \mathrm{~mol} / \mathrm{L}$, and the quantity adsorption of the $\mathrm{t}$-AC were not changed above $0.75 \mathrm{~mol} / \mathrm{L}$ of $\mathrm{Na}_{2} \mathrm{~S}_{2} \mathrm{O}_{8}$ solution.

Among the samples, the ATP/t-AC-1-0.75 catalyst possesses the lowest specific surface area but the best catalytic performance, suggesting that the specific surface areas of the studied catalysts are not the key issue to decide the catalytic performance for organic reaction. Refer to the previous literatures ,the larger accumulating oxygen-containing functional group are formed in the process of treating $\mathrm{AC}$ with oxidants solution and they occupied micropore site, leading to a decrease in micropore volume. 


\section{XRD and SEM Studies}

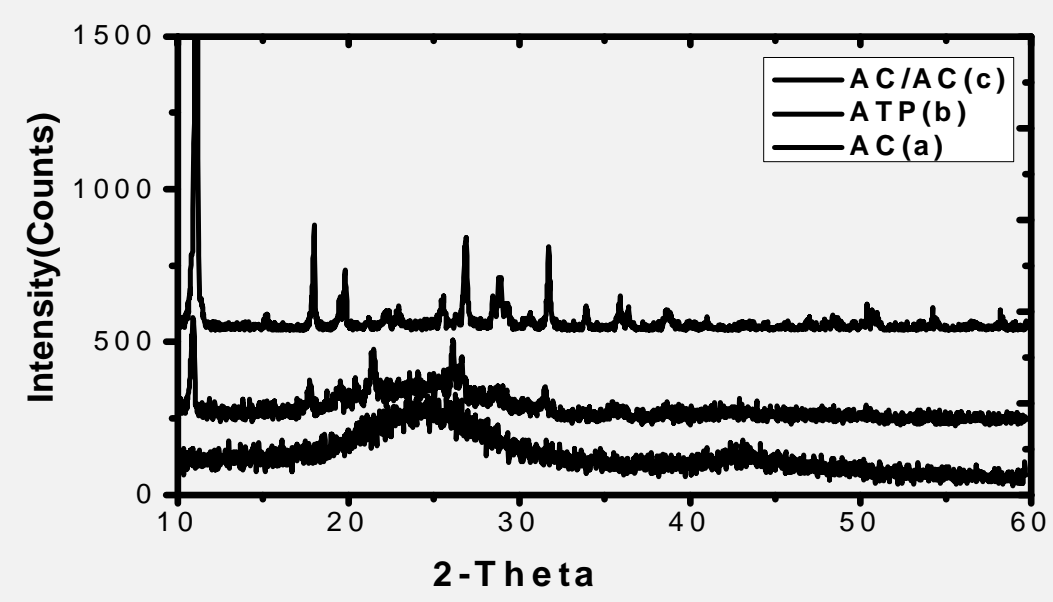

Fig6.XRD patterns of the t-AC, ATP and ATP/t-AC .
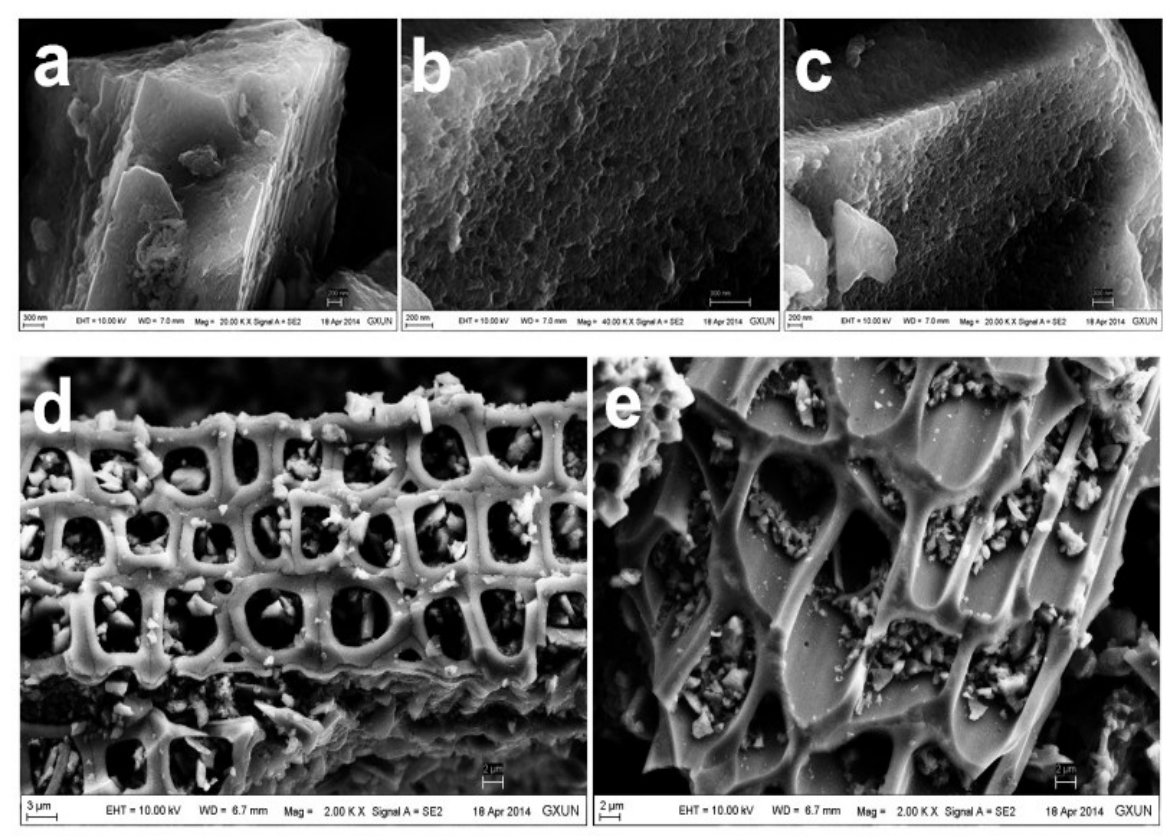

Fig.7 Typical TEM micrographs of t-AC and ATP/t-AC: a ut-AC b t-AC-1-0.75 c t-AC-2-1.0 The powder XRD patterns of the samples are shown in Fig 6. The XRD pattern exhibits one broad $\left(2 \theta=20-30^{\circ}\right)$ and another relatively weak $\left(2 \theta=40-50^{\circ}\right)$ diffraction peak, corresponding to the diffraction of AC, respectively. It is indicated that the prepared carbon materials are composed of aromatic carbon sheets and that is amorphous with relatively high BET surface area. Refer to the fig6(c), we can infer that ATP was loaded on the t-AC has relatively high BET surface area.

A reprehensive TEM micrograph of the t-AC (fig7a, b, c), ATP/t-AC (d, e) catalysts are shown in fig7. The u t-AC structure is regular structure. Refer to the fig (b, c), the t-AC-1-0.75 and t-AC-21.0 also has same regular structure. The pore structure of $\mathrm{AC}$ was not destroyed during the pretreatment by $0.75 \mathrm{~mol} / 1 \mathrm{Na}_{2} \mathrm{~S}_{2} \mathrm{O}_{8}\left(1.0 \mathrm{~mol} / \mathrm{LH}_{2} \mathrm{O}_{2}, 0.5 \mathrm{~mol} / \mathrm{LHNO}_{3}\right.$ separately). The ATP was Fully filled on the surface of the t-AC (fig7.e). The ATP/t-AC-1-0.75 and ATP/t-AC-2-1.0 catalyst exhibits the same highest catalytic performance for esterification and acidylation reaction as well as structure-performance relationship. 


\section{Conclusions}

To summarize, a simple and quick method is proposed for the preparation of the $\mathrm{t}$-AC supporting ATP that a solid acid catalysts. The ATP supported on the AC increase its specific surface area and improved its catalytic activity. The three ATP/t-AC catalysts namely ATP/t-AC-1, ATP/t-AC-2, ATP/t-AC-3 can be prepared for loading $60 \%$ ATP on $t-A C$ at $603 \mathrm{~K}$. The ATP/t-AC-1 catalyst is prepared by pretreatment the $\mathrm{u}$ t-AC with $0.75 \mathrm{~mol} / \mathrm{LNa}_{2} \mathrm{~S}_{2} \mathrm{O}_{8}$ that supporting ATP catalysts has highly catalytic activity. The ATP/t-AC-2 catalyst is prepared by pretreatment the u t-AC with $1 \mathrm{~mol} / \mathrm{LH}_{2} \mathrm{O}_{2}$ that supporting ATP. The ATP/t-AC-3 catalyst is prepared by pretreatment the u t-AC with $0.5 \mathrm{~mol} / \mathrm{LHNO}_{3}$ that supporting ATP. Pretreatment the u-AC with $\mathrm{Na}_{2} \mathrm{~S}_{2} \mathrm{O}_{8} / \mathrm{H}_{2} \mathrm{O}_{2} / \mathrm{HNO}_{3}$ ) are not changed the regular structure of $\mathrm{AC}$ but altered the hydrophilicity of catalyst (introducing oxygenated groups by controlling the oxidants concentration). The catalytic synthesis the tributyl citrate or aspirin show that the ATP/t-AC catalysts have developed highly activity and selectivity. The factor affect the AC activity for supporting ATP is the concentration of $\mathrm{Na}_{2} \mathrm{~S}_{2} \mathrm{O}_{8} / \mathrm{H}_{2} \mathrm{O}_{2} / \mathrm{HNO}_{3}$. When the concentration of $\mathrm{Na}_{2} \mathrm{~S}_{2} \mathrm{O}_{8}$ is increased to $0.75 \mathrm{~mol} / \mathrm{L}$, the yield of aspirin is increased to 86.6\%. When $\mathrm{H}_{2} \mathrm{O}_{2}$ is added, the activity of ATP/t-AC-2 is dramatically increased and the yield of aspirin is increased to $86.7 \%$. The activity of ATP/t-AC-3 is increased to $86.7 \%$ with the concentration of $\mathrm{HNO}_{3}$ increased to $0.5 \mathrm{~mol} / \mathrm{L}$. The catalytic reaction tests indicate that the ATP/tAC catalysts exhibit high activity and excellent recyclability.

\section{Acknowledgement}

The research was supported by the Science Fund Project of GuangXi Colleges and Universities (Project No KY2015YB445, 200103YB041, 2013YB105).

\section{References}

[1] Z Danlin, S L Liu, W J Gong, G H Wang, J H Qiu, H X Chen. Appl. Catal. A. 469 (2014) 284289

[2] P T Anastas, M M Kirchhhoff, Acc. Chem. Res. 35 (2002) 686-694.

[3] J M Desimone, Science 297 (2002) 799-803.

[4] P T Anastas, J B Zimmermann, Environ. Sci. Technol. 37 (2003) 94A-101A.

[5] E Lotero, Y Liu, D E Lopez, A Suwannakaran, D A Bruce, J G Goodwin, Ind.Eng. Chem. Res. 44 (2005) 5353-5363.

[6] J H D Boer, W J Visseren, Catal. Rev. 5 (1972) 55-66.

[7] K Eguchi, T Tokiai, H Arai, Appl. Catal. 34 (1987) 275-287.

[8] K Arata, H Matsuhashi, M Hino, H Nakamura, Catal. Today 81 (2003) 17-30.

[9] T Okuhara, Chem. Rev. 102 (2002) 3641-3666.

[10] K A Gabor . Somorjai. Catal Lett DOI 10.1007/s10562-014-1399-x.

[11] T Okuhara*, X Chen, H Matsuda. Applied Catalysis A: General 200 (2000) 109116.

[12] E Auer; A Freund; J Pietsch; T Tacke. Appl. Catal., A 1998, 173, 259-271.

[13] P Serp, M Corrias, P Kalck. Appl. Catal., A 2003, 253, 337-358.

[14] A Di Benedetto, G Landi, L Lisi, G Russo, Appl. Catal. B Environ. 142-143 (2013)169-177.

[15] D H Kim, D R Park, J Lee, Int. J. Hydrogen Energy 38 (2013) 4429-4436.

[16] B Qiao, A Wang, J Lin, L Li, D Su, T Zhang, Appl. Catal. B Environ. 105 (2011)103-110

[17] J L Ayastuy, E Fernández-Puertas, M P González-Marcos, Int. J. Hydrogen Energy 37(2012) $7385-7397$.

[18] M Glinski, G Zalewski, E Burno, A Jerzak Applied Catalysis A: General 470 (2014) 278-284.

[19] J Matos,A Corma. Appl. Catal., A 2011, 404, 103-112.

[20] P Makowski, R D Cakan,M Antonietti, F Goettmann, M M Titirici. Chem. Commun. (Cambridge, U. K.) 2008, 8, 999-1001.

[21] L R Radovic, F Rodriguez-Reinoso. Carbon materials in catalysis.In: Thrower PA, editor. Chemistry and physics of carbon, vol.25. New York; Dekker (CA, USA): American Carbon Society;1997. p. 243. 
[22] N Pernicone, M Cerboni, G Prelazzi, F Pinna, G Fagherazzi. Catal Today 1998;44:129-35.

[23] A E Aksoylu, M M A Freitas, J L Figueiredo. Catal Today 2000;62:337-46.

[24] M Gurrath, T Kuretzky, H P Boehm, L B Okhlopkova, A S Lisitsyn, V A Likhlolbov. Carbon 2000;38:1241-55.

[25] J C Wu,Z A Lin , F M Tsai, J W Pan. Catal Today 2000;63:419-26.

[26] A E Aksoylu, M Madalena , A Freitas, M F R Pereira , J L Figueiredo. Carbon 2001;39:17585 .

[27] V Priyanka, V Subbaramaiah, V C Srivastava , Indra Deo Mall. Separation and Purification Technology 125 (2014) 284-290

[28]A. Rey, M. Faraldos, J.A. Casas, J.A. Zazo, A. Bahamonde, J.J. Rodriguez, Appl. Catal. B Environ. 86 (2009) 69-77.

[29] N D Martínez, R B Venturini, H S Silva, J E González, A M Rodríguez, J. Mater. Res. 12 (2009) 45-50.

[30] A Heponiemi, L Rahikka, U Lassi, T Kuokkanen, Top. Catal. 54 (2011) 1034-1041.

[31]M Kang ,Y S Bae, C H Lee. Carbon 43 (2005) 1512-1516

[32]J Kang, H Wang, S J, J L Key, R F Wang. Power Sources. 251 (2014) 363-369

[33]Y Z Xiang, L N Kong, P Y Xie, T Y Xu, J GWang, and X N Li. Industial engineering chemistry research. 2014, 53, 2197-2203

[34] Y Li, X Chen, N J Gu. Phys. Chem. (B) 112(2008), 16647-16653. 